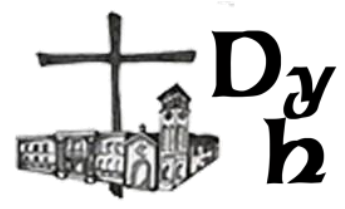

La maldad de la mentira

Diego José Bacigalupe

Dios y el hombre, vol. 5, n. 2, e082, 2021

ISSN 2618-2858 - https://doi.org/10.24215/26182858e082

https://revistas.unlp.edu.ar/DyH/index Cátedra libre de pensamiento cristiano - UNLP

Seminario Mayor San José

La Plata, Buenos Aires, Argentina

\title{
LA MALDAD DE LA MENTIRA
}

\author{
The Evil of Lying
}

Diego José Bacigalupe

diegojosebacigalupe@gmail.com

Seminario Mayor San José - La Plata - Argentina

\section{Resumen}

El autor muestra las razones de la maldad de la mentira según santo Tomás de Aquino y luego investiga si hay casos donde la mentira podría resultar buena.

Palabras claves: Verdad - Mentira - Suma de teología.

\section{Abstract}

Author shows, according Thomas Aquinas, why lying is bad. After that, he studies if there are some cases in which lying could be good.

Keywords: True - Lie - Summa theologiae. 
En el presente artículo intentaremos ahondar los fundamentos por los cuales mentir está mal. El propósito no es indagar la historia de la cuestión, sistematizar diversas posturas o contestar problemas actuales. Excelentes estudios cubren estas expectativas ${ }^{1}$. Lo que nos proponemos es, simplemente, poner de manifiesto dónde reside el problema de mentir, siguiendo lo que santo Tomás enseña en la Suma de Teología. Para ello plantearemos, en primer lugar, la relación entre las palabras, los conceptos y las cosas; luego, estableceremos dónde reside la verdad del discurso y su distinción de la veracidad como virtud; después, veremos en qué radica el mentir; por último, analizaremos las razones de la maldad del mentir, tocando incluso dos situaciones complejas, como son la mentira que salva una vida o el uso del hábito eclesiástico por parte de sujetos que no viven sus promesas de consagración.

\section{Palabras, conceptos, cosas}

En el célebre inicio del Peri hermeneias (Aristóteles, 1995, 16a, 3-8), Aristóteles sostiene que las palabras son signos de las afecciones del alma y que éstas son semejanzas de las cosas. Nuestro autor, entonces, establece una relación lineal ${ }^{2}$ :

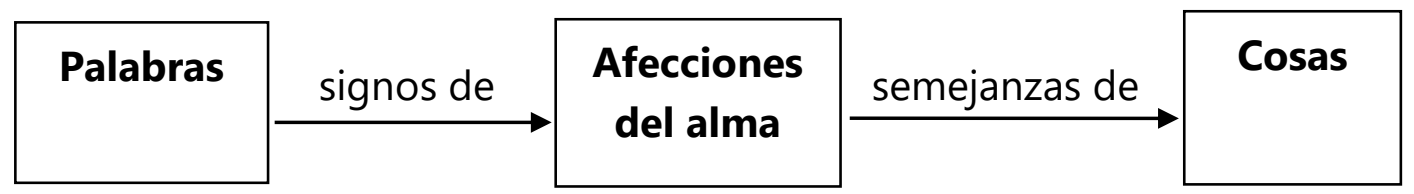

En primer lugar, vemos que las palabras son signos de las afecciones del alma. Por afecciones del alma podemos entender todo lo conocido sensiblemente e intelectualmente, toda sensación y todo concepto, pero, fundamentalmente, todo juicio, puesto que lo que en la mayoría de los casos expresamos con palabras son, justamente, juicios de la mente. A diferencia de las afecciones del alma, las

\footnotetext{
${ }^{1}$ Cf. Pérez Cortés (1998), González de Requena Farré (2019), Vide Rodríguez (2016), Mahon (2016), Gómez Giraldo (2018).

${ }^{2}$ También podría establecerse una relación entre las palabras y las cosas: se trataría de la suppositio de los medievales, por la cual una palabra hace las veces de la cosa en el discurso. De esta manera, pasaríamos de una línea al famoso triángulo semántico.
} 


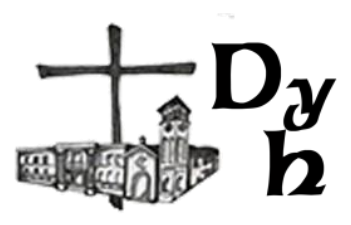

palabras son voces, sonidos articulados -aunque haya casos en los que se usan gestos en lugar de sonidos-, cargados de una cierta relación de razón (Contat, 2017, pág. 187-190) respecto de ciertas afecciones del alma.

¿Cuál es esta relación de razón? Esta relación de razón es la significación. Las palabras y las afecciones del alma no se parecen, no comparten ninguna cualidad, se trata de ciertos sonidos que, por convención humana, se refieren a ciertas realidades a través de la mediación de los conceptos. La multiplicidad de lenguajes expresa que la relación entre la palabra y las afecciones del alma es convencional: no existe un lenguaje que sea natural, aunque sí sea natural, por el hecho de ser sociales, hablar ${ }^{3}$. Los diversos lenguajes nos hacen ver que las palabras nacen de la voluntad de los hombres en su entendimiento mutuo y que se relacionan de algún modo con lo que los hombres quieren manifestar. Las palabras nos sirven para darnos a entender, para manifestar lo que está en nuestro interior.

¿Cómo es posible que nos entendamos? Nos entendemos porque las afecciones del alma a las que se refieren las palabras son las mismas para todos, como señala en el mismo lugar Aristóteles. Las afecciones del alma son semejanzas de las cosas: esto implica que comparten una cierta cualidad. Ser semejante, en efecto, es ser uno según la cualidad (Tomás de Aquino, 1950, IV, I. 2, 14):

La semejanza significa una relación -que requiere diversos sujetos- causada por la unidad de la cualidad; en efecto, la semejanza es la misma cualidad de cosas diferentes, de donde la razón que causa la semejanza expresa la unidad de la esencia, que es la misma bondad o sabiduría, o cualquier otra cosa que se significa por modo de cualidad (Tomás de Aquino, 1929-1947, l, d. 2, q. 1, a. 5, ex $)^{4}$.

\footnotetext{
${ }^{3}$ Los animales, cuanto más gregarios, más se comunican entre sí; así también el hombre, en su nivel intelectual, usa naturalmente de signos para darse a entender a los demás (Tomás de Aquino, 1979, I, 1).

4 "Similitudo enim significat relationem causatam ex unitate qualitatis, quae relatio requirit distincta supposita; est enim similitudo rerum differentium eadem qualitas; unde ratione ejus quod causat similitudinem ostendit unitatem essentiae, quae est eadem bonitas et sapientia, vel quidquid aliud per modum qualitatis significatur". Las traducciones de las citas de santo Tomás son nuestras.
} 
Esto implica que hay alguna cualidad compartida entre la cosa y la afección del alma. Esta cualidad puede ser accidental o bien, tomando la noción de cualidad en sentido amplio, puede ser la misma estructura formal que distingue a una cosa (Tomás de Aquino, 1888-1906, I-II, q. 49, a. 2, c). Hemos ahondado este punto en otra circunstancia (Bacigalupe, 2014). Aquí basta lo dicho para manifestar que nos entendemos porque nuestras palabras, aunque diversas en los distintos idiomas, se refieren a las mismas cosas a través de los mismos conceptos o sensaciones, y por eso, por ejemplo, es que podemos aprender un idioma que no es el materno.

Por lo dicho se entiende que usamos las palabras para manifestar los juicios internos que hacemos sobre las cosas o sobre nosotros mismos. Sea al avisar que <cerremos las ventanas porque va a llover>, al manifestar que <nunca he robado>, o al preguntar < ¿por qué hay que ir a la escuela?>, en todo caso las palabras nos sirven como signos sensibles para manifestar algo que hay en nuestro interior: sea un juicio sobre nosotros, sobre otras cosas, una duda, una pregunta, en todo caso las palabras expresan y dan a entender -con todas las limitaciones que implica un medio material- lo que hay en nuestro interior.

\section{Verdad y veracidad}

Cada una de las dos relaciones que hemos establecido, siguiendo a Aristóteles, puede ser adecuada o no. La verdad, en efecto, es la adecuación entre el intelecto y la cosa, según la célebre definición de Isaac Israelí (Tomás de Aquino, 1972-1976, q. 1, a. 1, c):

- Si los juicios del intelecto son adecuados al estado de cosas, se llaman verdaderos, como cuando pensamos <está lloviendo> $y$, efectivamente, llueve; mientras que se llaman falsos cuando tal adecuación no se da, como sería el caso contrario (pensar <está lloviendo> cuando no llueve).

- Si las cosas hechas por el hombre se adecuan a lo que este hombre pensó, se llamarán ellas verdaderas, puesto que son ellas las que se adecuan al intelecto: si un artesano quiere hacer una pulsera de cierto tipo según su invención (que llamaremos pulsera $R$ ) y, efectivamente, sale tal cual la pensó, será una verdadera pulsera $R$, por adecuarse a lo 


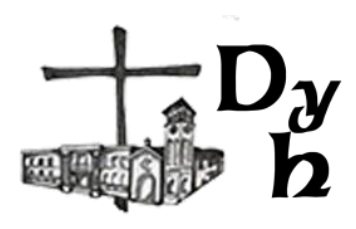

que pensó el artesano; por el contrario, si no sale tal cual la pensó, si, por ejemplo, sale larga como un collar -aunque resulte ser algo novedoso, en algún caso incluso una exitosa revolución de la moda, aprobada y mejorada por otros artistas-, será una falsa pulsera $R$, por no adecuarse a la idea original del artesano.

¿Cuál es el caso de los discursos proferidos? Puesto que hablar es algo que el hombre hace, el acto lingüístico se asemeja al caso del artesano, ya que ambos nacen de la capacidad humana de hacer. Así como el producto del arte será verdadero si se adecua a la idea del artesano, así el discurso será verdadero si se adecua a lo que hay en la mente del hablante. Asimismo, lo que hay en la mente del hablante podrá ser adecuado a la realidad, o no.

Un discurso podrá ser verdadero, entonces, de dos maneras:

- Será verdadero en cuanto a los signos si se adecua a lo que el hablante tiene en mente (adecuación de la palabra -y de los eventuales gestos concurrentes- al juicio del intelecto).

- Será verdadero en cuanto al contenido si lo que el hablante tiene en mente es adecuado a lo que realmente es (adecuación del juicio del intelecto a la realidad).

La veracidad, por otra parte, no es lo mismo que la verdad. Mientras que la verdad es la adecuación que hemos mencionado, la veracidad es una virtud, es un modo de obrar estable y bueno que inclina al hablante a decir lo que hay en su mente. Es una virtud relacionada con la justicia, en cuanto que intenta establecer una igualdad entre el juicio del intelecto y los signos exteriores (fundamentalmente las palabras) por las que se manifiesta. Es, por otra parte, una virtud que, aunque relacionándose con la justicia, no es exactamente igual a ella, puesto que esta última responde al débito legal, mientras que la veracidad sólo responde a un débito moral. Esto significa que decir lo que hay en la mente no realiza un débito de ley, sino un débito, por decir de algún modo, de honradez: los unos nos debemos a los otros decir lo que hay en nuestro interior. Como señala santo Tomás,

puesto que el hombre es un animal social, naturalmente un hombre debe a otro aquello sin lo cual la sociedad humana no puede ser conservada. Los hombres, en efecto, no pueden convivir juntos si no confían mutuamente, como 
manifestándose la verdad recíprocamente. Así, la virtud de la veracidad [verdad] en cierto modo alcanza la razón de débito (1888-1906, II-II, q. 109, a. 3, ad 1m)5.

Así pues, la virtud de la veracidad nos inclina a decir lo que hay en la mente, es decir, a que los signos por los que nos manifestamos se condigan con los juicios del intelecto (verdad en cuanto a los signos). Esto, obviamente, no garantiza que el discurso sea verdadero en cuanto al contenido, puesto que esto último más tiene que ver con la previa operación del intelecto, es decir, con la formación del juicio, el cual, como la experiencia nos enseña (muchas veces pensamos como verdadero lo que después descubrimos que no lo es), puede, por nuestra condición creatural y, aún más, material, errar.

\section{La mentira}

El hábito opuesto a la veracidad es la mendacidad, constituido por la propensión a decir mentiras. ¿Qué es la mentira? Santo Tomás resume lo que es la mentira de la siguiente manera:

$\mathrm{Si}$, pues, concurren estas tres cosas -esto es, que lo que se enuncie sea falso, que esté presente la voluntad de enunciar algo falso, y, por otra parte, la intención de engañar-, entonces hay falsedad materialmente, porque se dice algo falso; hay falsedad formalmente, a causa de la voluntad de decir algo falso; y hay falsedad efectivamente, a causa de la voluntad de fijar en la mente [del otro] la falsedad. Sin embargo, la razón de mentira se toma de la falsedad formal, esto es, de que alguien tenga la voluntad de enunciar algo falso (18881906, II-II, q. 110, a. 1, c) ${ }^{6}$.

La mentira, propiamente hablando, se reduce formalmente a la voluntad de enunciar algo falso, es decir, a romper la relación entre las palabras y los juicios de la mente. Es verdad que, como dice el texto citado, hay más de una

\footnotetext{
5 "Ad primum ergo dicendum quod quia homo est animal sociale, naturaliter unus homo debet alteri id sine quo societas humana conservari non posset. Non autem possent homines ad invicem convivere nisi sibi invicem crederent, tanquam sibi invicem veritatem manifestantibus. Et ideo virtus veritatis aliquo modo attendit rationem debiti".

6 "Si ergo ista tria concurrant, scilicet quod falsum sit id quod enuntiatur, et quod adsit voluntas falsum enuntiandi, et iterum intentio fallendi, tunc est falsitas materialiter, quia falsum dicitur; et formaliter, propter voluntatem falsum dicendi; et effective, propter voluntatem falsitatem imprimendi. Sed tamen ratio mendacii sumitur a formali falsitate, ex hoc scilicet quod aliquis habet voluntatem falsum enuntiandi". Subrayados nuestros.
} 


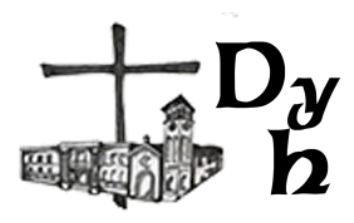

manera de decir falsedad. Por ejemplo, existe una falsedad meramente material, que no hace a la mentira. Esta falsedad no constituye mentira porque falta la voluntad de decir algo falso. Es decir, se dice algo falso, pero no intencionalmente. Veamos un ejemplo.

Supongamos que hablamos por teléfono con nuestra madre y dice que llega a las 7. Avisamos a nuestros hermanos que <mamá viene a las 7, es decir, en tres horas> (suponiendo que fueran las 16). Sin embargo, nuestra madre no viene a las 19, sino a las 7 de la mañana del día siguiente. ¿Nuestro discurso fue verdadero? No, fue falso, porque no hubo adecuación a lo que es. ¿Nuestro discurso fue una mentira? No, porque no hubo voluntad de decir algo falso: siempre pensamos que era verdad que nuestra madre venía a las 19. Así pues, en este caso hay falsedad material (porque el discurso no era verdadero según el contenido), pero no hay falsedad formal, es decir, mentira (porque el discurso sí era verdadero según los signos).

En el ejemplo visto, encontramos las dos líneas de adecuación mencionadas previamente en juego y en discordancia:

- Verdad según el contenido del discurso: es la adecuación entre el intelecto y la cosa, ausente en el ejemplo citado. Por eso este discurso es materialmente falso.

- Verdad según los signos del discurso: es la adecuación entre las palabras -y los gestos- y lo que hay en la mente, presente en el ejemplo citado. Por eso este discurso es formalmente verdadero.

En cuanto a la falsedad efectiva, es evidente que está ausente en el ejemplo: en ningún caso quisimos engañar a nuestros hermanos.

Pongamos otro ejemplo. Supongamos que nuestra madre nos dice por teléfono que llega a las 7. Nosotros suponemos que llega a las 19, pero, como queremos ser los únicos en recibirla, les decimos a nuestros hermanos: <mamá llega a las 7 de mañana a la mañana>. De esa manera, seremos los únicos en recibirla y, además, podremos disfrazar el engaño, señalando astutamente una supuesta confusión. Sin embargo, nuestra madre efectivamente llega a las 7 de la mañana del día siguiente... ¿Cómo analizamos esta situación?

Por un lado, hay que decir que la proposición <mamá llega a las 7 de mañana a la mañana $>$-que nosotros considerábamos falsa- resulta verdadera, porque efectivamente se da así. Es decir, es materialmente verdadera, en cuanto 
que el contenido se adecuó, accidentalmente, a la realidad. Por otro lado, la misma proposición según los signos del discurso es falsa, esto es, formalmente falsa, porque en nuestra mente había otra cosa: pensábamos que era verdad que mamá llegaba a las 19 y dijimos que llegaría a las 7 de la mañana; luego, los signos no se adecuaron al juicio del intelecto $y$, por esto, hubo voluntad de decir algo falso, es decir, hay falsedad formal.

En cuanto a la falsedad efectiva, no hay dudas de que aquí estuvo presente, porque siempre hubo intención de engañar.

Así pues, mientras que en el primer caso no hubo mentira, puesto que no hubo voluntad de decir algo falso, en el segundo caso sí. Es decir, la mentira reside formalmente en la inadecuación voluntaria entre los signos y los significados, entre las palabras y lo que hay en la mente. Cabe destacar que es preciso que sea voluntaria; de no ser así, no habría mentira, puesto que no habría un acto moral.

Dicho esto, la cuestión recae sobre la falsedad formal, que es la que constituye la mentira. Siempre que haya voluntad de decir algo falso (aunque lo que se diga sea materialmente verdadero), habrá mentira.

\section{Razones de la maldad de la mentira}

Santo Tomás esgrime dos razones de la maldad de la mentira. La primera es la ya mencionada: la convivencia social se vuelve imposible si los hombres no pueden fiarse unos de otros. Existe un débito moral, la honradez mutua, que hace que decir la verdad sea preciso para la convivencia social ${ }^{7}$.

La segunda razón no atiende a la sociabilidad natural del hombre, sino a la naturaleza de las palabras:

La mentira es mala por su género, puesto que es un acto que cae sobre materia indebida, ya que las voces son naturalmente signos de lo entendido, es antinatural e indebido que alguien por cierta voz signifique lo que no tiene en mente (Tomás de Aquino, 1888-1906, II-II, q. 110, a. 3, c) ${ }^{8}$.

\footnotetext{
${ }^{7}$ El dilema del prisionero pone a prueba justamente esto, viendo que la ganancia neta de la confianza mutua, a pesar de pérdidas circunstanciales, es superior (Miller Moya, 2004, págs. 111-113).

8 "Mendacium autem est malum ex genere. Est enim actus cadens super indebitam materiam, cum enim voces sint signa naturaliter intellectuum, innaturale est et indebitum quod aliquis voce significet id quod non habet in mente".
} 


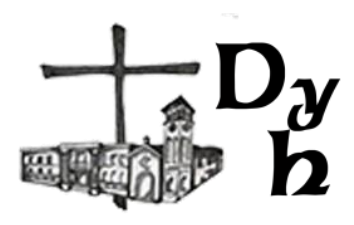

Por su propia naturaleza, las palabras (aquí llamadas voces, pero incluyendo todo gesto que pueda significar algo que haya en la mente) son signos de lo que hay en la mente, es decir, han sido instituidas para eso, las usamos para decir, preguntar, advertir, expresar, en síntesis, manifestar lo que hay en nuestro interior. Si fuéramos por un camino de cornisa y encontráramos que una flecha nos indica doblar hacia el lado donde se halla el abismo, entraríamos en una confusión que, por ejemplo, de noche podría ser fatal. Así como las señales de tránsito han sido instituidas para indicar algo del camino, así las palabras han sido instituidas para indicar algo de lo que hay en nuestra mente. Utilizar los signos para significar lo que no hay en la mente es contrario a la propia naturaleza de las palabras.

Así pues, la mentira es de por sí mala, siempre y en todos los casos: no existe excepción a esta realidad. No hay modo de volver lo malo bueno: Bonum ex integra causa, malum ex quocumque defectu. La mentira, de por sí, incluye un defecto: voluntariamente no adecua los signos a los significados, es decir, a lo que hay en la mente del hablante.

Esto es válido incluso en el caso de la restricción mental (Drake, 1997). Dejando afuera los diversos tipos (amplia, estricta), la restricción mental es la formulación de un enunciado lo suficientemente ambiguo como para, por un lado, contener palabras que no vayan contra lo que hay en la mente del hablante y, por otro lado, provocar en el oyente la comprensión de lo contrario de lo que se piensa. Por ejemplo, supongamos que viene una persona que quiere ver a nuestro padre, pero que sabemos que nuestro padre no la quiere encontrar. Al ver por la ventana quién es quien llama a la puerta, le decimos a nuestro padre que salga al patio trasero de la casa, atendemos $y$, cuando esta persona pide hablar con él, le decimos <recién salió>. Mientras que nosotros entendemos que salió al patio, la persona que está en la puerta entiende que salió de la casa, es decir, que no está en el domicilio. Como los signos se adecuan a lo que hay en nuestra mente, aparentemente, no hay una mentira.

En efecto, el problema de la restricción mental parece estar más en la voluntad de engañar (falsedad efectiva) que en la enunciación voluntaria de algo contrario a lo que sabemos verdadero (falsedad formal), en el aspecto ilocucionario más que en el locucionario. Como la mentira consiste en la falsedad formal, entonces, la restricción mental no sería mentira. 
Sin embargo, como ya hemos dicho, la restricción mental se vale de un enunciado ambiguo: mientras que para el hablante significa una cosa, para el oyente significa otra. Esto sucede también cuando se da un error en la comprensión, pero la restricción mental es más que un error, puesto que no es casual, sino voluntaria. En la restricción mental, las palabras se eligen de manera tal que puedan significar -ayudadas eventualmente por el contexto- algo distinto de lo que hay en la mente del hablante. Por lo tanto, también hay falsedad formal: los signos son elegidos a propósito para que, en esta circunstancia, signifiquen para el oyente algo distinto de lo que el hablante sabe que es verdadero, induciendo al pensamiento erróneo. Así pues, la restricción mental, como todo enunciado que usa signos que no se adecuan al significado voluntariamente, es una mentira. Y, como toda mentira, es de por sí mala.

Siempre se erige una serie de objeciones a la afirmación de que toda mentira es mala: por ejemplo, cuando una mentira salva una vida, o la mentira que se hace al enemigo, que resultaría no ser mala. Santo Tomás, fiel a su posición inicial, considera que todas estas mentiras (como también las bromas) son mentiras $y$, por lo tanto, contrarias a la naturaleza de los signos $y$ moralmente objetables, pero establece una distinción entre las mentiras que van contra la caridad y aquellas que no, es decir, entre las que constituyen pecado mortal y aquellas que no lo hacen. Así, las mentiras que van contra Dios -cuya verdad se altera o cuya dignidad se ofende- o contra el prójimo -cuya verdad para su verdadero desarrollo personal se oculta o cuya fama o cuyos bienes son dañados- son faltas graves, mientras que cuando recae sobre verdades sin importancia, cuando procura la risa o cuando incluso procura ser útil al prójimo, no será grave (Tomás de Aquino, 1888-1906, II-II, q. 110, a. 4, c). Asimismo, podemos agregar nosotros, las mentiras que nacen del miedo, por ejemplo, carecen de la voluntariedad necesaria para que sean consideradas un acto moral. De todos modos, la voluntad deliberada y libremente determinada de decir algo falso siempre es mentira y la mentira siempre, aunque en distintos grados, es moralmente mala.

De todos modos, ¿cómo resolver el problema de decir una verdad que puede comprometer la vida de alguien? Si unos hombres armados entran en un edificio buscando, digamos, a nuestro jefe para matarlo -independientemente de cuán bien nos llevemos con nuestro jefe-, y nos preguntan a punta de 


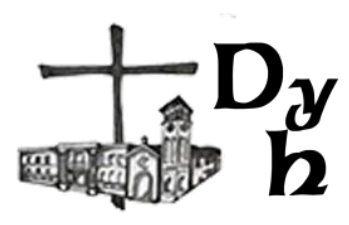

pistola dónde está, ¿qué contestamos? Sabemos que está en el subsuelo. Podemos salvarle la vida si los mandamos al cuarto piso y le damos tiempo para huir. Pero, si decimos esto, nuestras palabras no se adecuarán a lo que hay en nuestra mente, y no será un acto bueno, aunque tampoco un pecado mortal ${ }^{9}$. ¿Qué hacer?

Santo Tomás se plantea, mutatis mutandis, esta misma cuestión:

Además, el mal menor debe ser elegido para evitar un mal mayor, como el médico amputa un miembro para que no se corrompa todo el cuerpo. Pero menor daño es que alguien induzca una opinión falsa en el ánimo de otro respecto de que alguien mate o sea asesinado. Por lo tanto, lícitamente el hombre puede mentir para preservar a uno del homicidio, y, a otro, de la muerte (1888-1906, q. 110, a. 3, arg. 4) ${ }^{10}$.

Y la contesta de la siguiente manera:

La mentira no sólo tiene razón de pecado por el daño que infiera al prójimo, sino [también] por su desorden. Pero no es lícito usar de algún ilícito desorden para impedir daños y defectos de los demás, como no es lícito robar para hacer limosna (salvo ocasionalmente, en el caso de necesidad, en el que todas las cosas son comunes). $Y$ por esto no es lícito decir una mentira para que alguien libre a otro de algún peligro. Sin embargo, es lícito ocultar prudentemente la verdad bajo cierto disimulo, como dice [san] Agustín, en Contra mendacium (1888-1906, II-II, q. 110, a. 3, ad 4m) ${ }^{11}$.

\footnotetext{
${ }^{9}$ Se trataría de una mentira oficiosa, es decir, útil para otro. La mentira oficiosa se distingue de la jocosa, cuya finalidad es la diversión, y de la perniciosa, que nace de la malicia.

10 "Praeterea, minus malum est eligendum ut vitetur maius malum, sicut medicus praecidit membrum ne corrumpatur totum corpus. Sed minus nocumentum est quod aliquis generet falsam opinionem in animo alicuius quam quod aliquis occidat vel occidatur. Ergo licite potest homo mentiri ut unum praeservet ab homicidio, et alium praeservet a morte".

11 "Ad quartum dicendum quod mendacium non solum habet rationem peccati ex damno quod infert proximo, sed ex sua inordinatione, ut dictum est. Non licet autem aliqua illicita inordinatione uti ad impediendum nocumenta et defectus aliorum, sicut non licet furari ad hoc quod homo eleemosynam faciat (nisi forte in casu necessitatis, in quo omnia sunt communia). Et ideo non est licitum mendacium dicere ad hoc quod aliquis alium a quocumque periculo liberet. Licet tamen veritatem occultare prudenter sub aliqua dissimulatione, ut Augustinus dicit, contra mendacium".
} 
Más allá de todas las consideraciones que habría que hacer en torno a este tipo de situaciones, en las que, cuanto más querida sea la persona en riesgo, más premura tendremos por salvar su vida, en abstracto y en frío, por decir de algún modo, hay que sostener que la mentira es un medio ilícito para un fin lícito. El cierto disimulo mencionado por santo Tomás no podría ser, por lo ya dicho, una restricción mental; sólo el silencio es el disimulo posible de la verdad. Así pues, no es lícito mentir para salvar la vida del jefe, en el ejemplo aducido, pero sí es posible ocultar la verdad con disimulo, es decir, con silencio $^{12}$. En efecto, no es lo mismo decir lo que no es que callar. La virtud de la veracidad se opone a usar de signos que no respondan a lo que hay en la mente, pero no se opone al silencio. Esto es verdadero en el ejemplo dado, pero también en aquellos casos donde no se dice todo lo que se es, sin negar lo que en verdad se es; es decir, por ejemplo, cuando una persona no dice de sí lo que tiene de sabio o santo, pero tampoco lo niega, obra prudentemente y no va contra la virtud de la veracidad (Tomás de Aquino, 1888-1906, II-II, q. 109, a. 4, c).

Cabría preguntarse si, dada esta situación, un consagrado que viste un hábito y que ha caído en pecado mortal, ¿no debería dejar de usar el hábito? En efecto, el hábito hace las veces de palabra en este caso, puesto que es un signo exterior de una realidad interior. Significa, pues, la consagración a Dios, pero, de hecho, esa consagración ha sido pervertida por el pecado, luego, parece una mentira, es más, parece hipocresía, que use el hábito.

A esta situación, santo Tomás contesta con una claridad admirable:

El hábito de santidad -por ejemplo, de religión o de clerecía- significa el estado por el que alguien se obliga a las obras de perfección. Por esto, cuando alguien asume el hábito de santidad, tendiendo a alcanzar el estado de perfección, si por debilidad defecciona, no es simulador o hipócrita, porque no está obligado a manifestar su pecado dejando el hábito de santidad. Si, en cambio, asumiera

\footnotetext{
12 En esto nos apartamos de Gómez Giraldo: "Por mi parte, considero que la mentira por humanidad es obligatoria, y a fortiori la restricción mental" (2018, pág. 84). Obviamente, en estos casos la mentira no es pecado mortal -no atenta contra la caridad-, pero, de todos modos, es un medio ilícito. Aún el confesor debe preferir, a nuestro entender, evitar la cuestión (manifestando su imposibilidad de hablar de esos temas en general) a mentir para ocultar el secreto de confesión.
} 


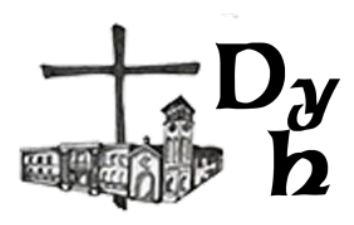

este hábito de santidad para ostentar ser justo, sería hipócrita y simulador (1888-1906, II-II, q. 111, a. 2, ad 2m) ${ }^{13}$.

El hábito, pues, es un signo del estado que se prometió abrazar; luego, la defección circunstancial no implica el abandono del hábito, porque éste no significa la santidad actual, sino la decisión de tender hacia ese estado de perfección. Ahora bien, si desde el principio no hubo intención de abrazar el estado de perfección, entonces sí hay mentira y, por lo tanto, debería abandonar el hábito. De hecho, de esta situación podrían seguirse grandes y graves problemas por la posición en que pone a alguien el uso de un hábito. Como salta a la luz por oposición, la veracidad, dado que es una virtud moral, aún en estas cosas, no sólo nos hace obrar bien, sino que nos hace buenos.

\section{Conclusión}

Las razones por las que la mentira es mala son dos:

- La mentira atenta contra la naturaleza social del hombre: La vida en sociedad implica la honradez mutua; de otro modo, la convivencia social se hace imposible. Esto se apoya, evidentemente, en la justicia, que es la estructura de la sociedad. Una sociedad sin relaciones justas se desintegra. Y esto vale para todos los niveles sociales: la familia, el barrio, la escuela, la parroquia, las instituciones de ayuda mutua, el club, la ciudad, la república.

- La mentira atenta contra la naturaleza del signo lingüístico: La palabra (oral, escrita o gestual) es un signo de las afecciones del alma; utilizarla para significar lo que no hay en el alma, sea algo falso sobre las cosas o sobre nosotros mismos, va contra lo que el mismo signo es y constituye un acto contrario a la naturaleza de las palabras. Y esto vale para todas las situaciones, sin excepción.

Asimismo, vale la pena decirlo, es claro que, aunque toda mentira sea pecado, no toda mentira es pecado mortal; para ser pecado mortal debe ser

\footnotetext{
13 "Ad secundum dicendum quod habitus sanctitatis, puta religionis vel clericatus, significat statum quo quis obligatur ad opera perfectionis. Et ideo cum quis habitum sanctitatis assumit intendens se ad statum perfectionis transferre, si per infirmitatem deficiat, non est simulator vel hypocrita, quia non tenetur manifestare suum peccatum sanctitatis habitum deponendo. Si autem ad hoc sanctitatis habitum assumeret ut se iustum ostentaret, esset hypocrita et simulator".
} 
contraria a la caridad. Pero esto no es lo que nos interesa aquí, sino simplemente poner en evidencia la radical necesidad de vivir en la verdad, más allá de que, prudentemente, en ciertos casos valga la pena más callar que hablar:

Aquí en el mundo la verdad anda en despojo y humillación, no tiene donde recostar su cabeza, debe agradecer que alguien le ofrezca un vaso de agua pero si alguien lo hace, si la reconoce por lo que es, a viva voz y públicamente, entonces esta insignificante figura, esta pobre desgraciada, ultrajada, burlada, perseguida, «la verdad», tiene, si puedo decirlo así, una pluma en su mano con la que escribe en un papel «por la eternidad» y se lo entrega a ese hombre que en la contemporaneidad la reconoció por lo que es (Kierkegaard, 2006, pág. 162).

Por el contrario, la mundanidad, esto es, la degradación del hombre que hace de esta tierra y de su posición en ella su paraíso, es contraria a la verdad: el engaño es el poder, y la mentira, que puede iniciarse inocentemente pero que conduce a cosas graves, es el medio para instalarse y acomodarse en cualquier situación o institución. Mientras que Jesucristo fue enjuiciado por las mentiras de la mundanidad religiosa de su tiempo (Mt 26, 59-62; Mc 14, 55-59), Él, que es nuestro Maestro y nuestro Camino, Él, que es la Verdad, algunas veces calló ${ }^{14}$, pero jamás mintió ${ }^{15}$.

\section{Bibliografía}

Aristóteles (1995): Sobre la interpretación, en Aristóteles: Tratados de lógica (órganon), II. Gredos, Madrid, pp. 22-81.

\footnotetext{
${ }^{14}$ Hay quienes consideran que Jesucristo ha hecho restricciones mentales: "El mismo Jesucristo nos dio un buen ejemplo de restricción mental cuando dijo que el Hijo de Dios no sabía la fecha del Juicio final (Mar. XIII, 32). No lo sabía con ciencia comunicable, pero en rigor lo sabía, como aseguraron todos los Padres en sus controversias con los arríanos [sic] apolinaristas, nestorianos, monofisitas, etc." (Manuel, 2012). Considerar esto una restricción mental es semejante a sostener que, cuando Jesús dijo "el Padre es más grande que Yo" (Jn 14, 28) o "Dios mío, Dios mío, ¿por qué me has abandonado?" (Mt 27, 46) -esta última cita tomada según ciertas interpretaciones-, estaría haciendo también restricciones mentales, porque su discurso se refiere en ambos casos a su humanidad y no a su divinidad. Como es evidente, no son restricciones mentales, son cuestiones de exégesis.

${ }^{15}$ Agradecemos profundamente las indicaciones y sugerencias de estilo, de claridad y de bibliografía que nos han hecho llegar los revisores.
} 


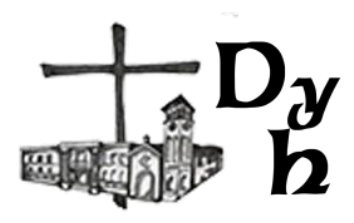

Bacigalupe, D. J. (2014): Las representaciones mentales en santo Tomás de Aquino. EDUSC, Roma.

Contat, A. (2017): Un'analisi del segno linguistico nella prospettiva di san Tommaso d'Aquino, en A. Contat, Miscellanea in onore di Marco Arosio, Roma, Ateneo Pontificio Regina Apostolorum, págs. 173-206.

Drake, A. (1997): Restricción mental y mentira. «Estudios Eclesiásticos», 281(72), págs. 341-345: recuperado en enero de 2022 de https://revistas.comillas.edu/index.php/estudioseclesiasticos/article/view/ 12008.

Gómez Giraldo, A. (2018). Breve tratado sobre la mentira. Programa Editorial Universidad del Valle: recuperado en enero de 2022 de https://bibliotecadigital.univalle.edu.co/handle/10893/18553

González de Requena Farré, J. A. (2019): La conceptualización de la mentira en tiempos de la posverdad. «Universitas Philosophica», 72(36), págs. 97-123: https://doi.org/10.11144/Javeriana.uph36-72.cmtp

Kierkegaard, S. (2006): El Instante. Trotta, Madrid.

Mahon, J. E. (2016): The Definition of Lying and Deception. The Stanford Encyclopedia of Philosophy (Winter 2016 Edition), E. N. Zalta (ed.): https://plato.stanford.edu/archives/win2016/entries/lying-definition/

Manuel (2012): Mandamientos séptimo y octavo. Interés y usura. La mentira. Restricción mental. El Fin no justifica los medios. Fundación San Vicente Ferrer: recuperado en enero de 2022 de http://fundacionsanvicenteferrer.blogspot.com/2012/10/mandamientosseptimo-y-octavo-interes-y.html

Miller Moya, J. L. (2004): Acción colectiva y modelos de racionalidad. «Estudios Fronterizos», 9(5), págs. 107-130: recuperado en enero de 2022 de http://www.scielo.org.mx/pdf/estfro/v5n9/v5n9a5.pdf

Pérez Cortés, S. (1998): La prohibición de mentir. Siglo XXI editores, México DF Madrid.

Tomás de Aquino (1888-1906): Summa Theologiae [Editio Leonina, Tomos IVXII]. Typographia Polyglotta S. C. de Propaganda Fide. Romae.

Tomás de Aquino (1929-1947): Scriptum super libros Sententiarum. Tomos I-IV, Lethielleux, Parisiis. 
Tomás de Aquino (1950): In duodecim libros Metaphysicorum Aristotelis expositio. Marietti, Taurini - Romae.

Tomás de Aquino (1972-1976): Quaestiones disputatae de Veritate [Editio Leonina, Tomo XXII/1-3]. Editori di san Tommaso, Roma.

Tomás de Aquino (1979): De Regno ad regem Cypri [Editio Leonina, Tomo XLII]. Editori di san Tommaso, Roma.

Vide Rodríguez, V. (2016): Análisis filosófico y teológico de la mentira desde la teoría de los actos de habla. «Perseitas», 4(2), págs. 153-175: https://doi.org/http://dx.doi.org/10.21501/23461780.2011 